\title{
A Thematic Review on Research Integrity and Research Supervision: Relationships, Crises and Critical Messages
}

\author{
Abdulghani Muthanna ${ }^{1} \cdot$ Ahmed $^{\text {Alduais }}{ }^{2}$
}

Published online: 7 May 2020

(C) The Author(s) 2020

\begin{abstract}
This article focuses on reporting the relationship between research integrity and research supervision. Initially, it briefly discusses the positive research supervision. By following a detailed thematic analysis methodology, 66 published sources were compiled, disassembled, reassembled and interpreted. The findings of this study highlight that maintaining research integrity is the responsibility of all, and that more responsibility falls onto the shoulders of instructors and supervisors who need to ethically perform research supervision to maintain further research integrity. Further, they show crises related to how research supervision is at danger, and how danger at supervision exists. The insights reported in this study help raise further awareness towards effective research supervision that in return and in effect enhances the overall research integrity. The review also concludes with three critical messages (for higher education policymakers, administrators, instructor/supervisors, and students/supervisees) for a practical implementation.
\end{abstract}

Keywords Research integrity $\cdot$ Research supervision $\cdot$ Research ethics $\cdot$ Supervisors $\cdot$ Supervisees

\section{Introduction}

Research supervision, be it for master thesis, doctoral dissertation, or instructional courses, is to help students develop critical, creative thinking and research skills, and contribute to the existing body of knowledge (e.g. Anderson et al. 2006). It demands many skills on the part of supervisors. In other words, the quality of the work production depends to some extent on the

Abdulghani Muthanna

am96715@gmail.com; abdulghani.muthanna@oslomet.no

Ahmed Alduais

ibnalduais@gmail.com

1 Department of International Studies and Interpreting, Faculty of Education and International Studies, OsloMet - Oslo Metropolitan University, Oslo, Norway

2 Institute of International \& Comparative Education, Faculty of Education, Beijing Normal University, Beijing, People's Republic of China 
supervision quality such as supervisory style and students' learning needs and patterns (e.g. Hemer 2012). Effective quality preparation of master students helps supervisees differentiate between critical (effective) and destructive feedback during their doctoral studies. Committed scholars/supervisors encourage students' being critical, and avoid thwarting their supervisees. Thwarting students however reflects a lack of following the teaching and research ethics that educational researchers must 'provide proper training and supervision to their students, supervisees' (Educational Researchers 2011, 155). Further, providing destructive feedback is not ethical, and hinders students' creativity (Meng et al. 2017). Moreover, the unequal treatment toward students for unknown reasons represents a violation of the academic laws stated in the following quotes:

Education researchers do not engage in discrimination in their work based on race; ethnicity; culture; national origin; gender; sexual orientation; genderidentity; age; religion; language; disability .... or any other applicable basis proscribed by law (Educational Researcher 2011, 147).

Education researchers who serve as teachers, trainers, or administrators of education and training programs perform their responsibilities conscientiously, competently, and with integrity. They model and foster ethical behavior for their students and trainees (Educational Researcher 2011, 154).

Providing proper supervision is the ethical responsibility of all educational supervisors who are ethically obliged to care for their supervisees' development of knowledge and behavior (Löfström and Pyhältö 2018). Fostering ethical behavior for students enhances students' honesty in general and research conduction in particular. Supervisors' conscientious feedback helps keep the research process ongoing (e.g. Shute 2008) and motivates students to accomplish the tasks (de Kleijn et al. 2013) competently.

Despite the presence of several codes of ethics concerning the application of research supervision activity (e.g. the above quotes), there are still many cases reporting on students' supervision dissatisfaction, abusive supervision, and sexual abuse (detailed in the next sections). The interpretation of such happenings implies less mastery of knowledge of research supervision and/or research ethics and commitments. This poor or abusive supervision makes supervisees complain publically (see for example, Quora, https://www.quora.com/search?q= research+supervision). These complaints accentuate the significance of the supervision activity and the urgent need for supervisors to be well prepared for performing it ethically and professionally. The involvement of one-third scientists in inadequate research practices (Martinson et al. 2005as cited in Kuroki 2018) reflects a serious danger affecting research integrity. The destroying danger is that such scientists are either teaching instructors and/or research supervisors, and this poses these two important questions: What is the relationship between research supervision and research integrity? Is supervision at danger or is there danger at supervision? Therefore, this critical review paper attempts to answer these two critical questions, and provide insights for implementers (policymakers and administrators, supervisors, and supervisees) for a practical implementation.

\section{A Brief Synthesis of Positive Research Supervision and Experience}

Before detailing on the research methodology and reporting the relationship between research integrity and research supervision, and how negative research supervision 
affects supervisees' academic performances and personal lives -reflecting supervisors' lack of ethics and commitment in one way or another, this brief synthesis is ethically to acknowledge the actual presence of positive research supervision that of course leads to supervisees' positive experiences worldwide. There is no dispute that many research supervisors are highly committed and devoted to providing the best supervision to their supervisees. They are totally aware of achieving the main purpose of the research supervision (assisting supervisees in developing critical, creative thinking and research skills), and strategically approach the activity (e.g., performing like an emancipator, a functionalist, an evaluator, a critical-thinking developer, motivator or using a mix of such approaches), taking into consideration supervisees' cultural backgrounds and expectations (Lee 2008, 2018). The critical thinking and research skills development enables supervisees to conduct scientific research that contributes to the body of knowledge (e.g. Anderson et al. 2006) and avoid committing any form of research misconducts, intentional plagiarism in particular (e.g., Walker 1998; Walker and White 2014).

Furthermore, the committed scholars make the supervision activity enjoyable and fruitful. For example, being highly aware of the importance of the supervision activity and its connection to supervisees' future research honesty, these committed scholars carefully apply the research ethics codes, falling not into the trap of conducting any form of abusive supervision. They do all their best to assist supervisees (doctoral students in particular) to stand on their own feet (e.g. Lovitts 2008). In addition to their being well versed in their fields of specialty areas, they have also developed a sufficient awareness toward understanding the perceptions and body expressions of their supervisees. This in return helps in effectively communicating with supervisees (Nilsson 2007), fearing not the occurrence of misunderstandings.

These committed scholars are also aware of the importance of learning about the different cultures and norms, and even purposively tend to discuss cultural issues and norms with their supervisees in the initial sessions. This is specifically useful in lessening the stress supervisees might go through; an important dimension in increasing the supervisees' self-trust and the overall trust toward supervisors and the supervisory activity (Killian 2001). Meanwhile, the devoted scholars offer quality supervision because they received quality supervision or they become determined not to make their supervisees suffer the same way they did in their student days. This is further detailed in the following quote, which is a supervisors' response to the question of 'why do you supervise the way you do?' conducted by the University of Sydney's Institute for Teaching and learning on the Research Higher Degree Supervision Development Program:

In some cases, supervisors say that they supervise the way they were themselves supervised. Put simply: good supervision begets good supervision. It is the logic of the trickle-down effect. In other cases, supervisors tell us that their practice has been a reaction against their experience of being supervised. Their focus is now on ensuring that their students are protected from either benign neglect or over-supervision (Milgate 2006, 93-94).

Performing research supervision ethically and loyally drives supervisees to (un)consciously appreciate their supervisors' efforts. There are several studies that report upon supervisees' positive experiences with research supervision. For example, the results of the Postgraduate Research Experience Survey [PRES] (2019) show a high rate of postgraduates' satisfaction toward research supervision. Following is a detail of the study methodology. 


\section{Research Methods}

This is a qualitative study following the content/thematic analysis method. The analysis phases begin with compiling data and end with critical, concluding remarks. Constructionism informs the epistemological bases of this study with reference to theoretical perspectives from interpretivism and grounded theory methodological tools - using the content/thematic analysis methods. The deductive approach analysis using this framework has led to the identification of three significant themes. The first theme shows the strong relationship between research integrity and research supervision. The second discusses how research supervision is at danger while the third theme reports upon the sad reality that, due to some research supervision practices, there is then danger at supervision.

\section{Research Sampling}

In theory, the sample of this study is supervisors and supervisees of undergraduate, graduate and postgraduate studies. However, since the study does not have any direct intrusion with humans so the sampling used the published literature available on scientific and research databases. These included: ScienceDirect (https://www.sciencedirect. com/), Scopus (https://www.scopus.com/), Google Scholar (https://scholar.google.com/), Taylor and Francis Journals (https://taylorandfrancis.com/journals/) and SAGE publications (https://journals.sagepub.com/). The search terms included: research supervision, research integrity, research ethics and supervision. The final selection of the papers was based on the relevance of the accessed papers to these four main searching words and their relevance to higher education research. The following figure shows the sampling framework used in this paper (Fig. 1).

This paper aimed at exploring the relationship between research integrity and research supervision through analysing previously published research on different contexts, albeit, comparing context differences is not within the scope of this paper. Hence, the generated output of this paper, based on the thematic analysis, relates to any higher education institution and/or research centre wherein the research supervision activity is at practice.

\begin{tabular}{|l|l|}
\hline $\begin{array}{l}\text { Theoretical population } \\
\text { - Research integrity } \\
\text { - Research supervision } \\
\text { - Supervisors } \\
\text { - Supervisees }\end{array}$ & $\begin{array}{l}\text { Accessible population } \\
\text { - Published research online }\end{array}$ \\
\hline \multicolumn{2}{|l|}{ Sampling framework } \\
\hline $\begin{array}{l}\text { Sampling frame } \\
\text { - Online databases }\end{array}$ & $\begin{array}{l}\text { Sample } \\
\text { 66: papers, books, manuscripts } \\
\text { and policy documents }\end{array}$ \\
\hline
\end{tabular}

Fig. 1 Sampling framework 


\section{Research Measures}

The study made use of an unobtrusive measure where there is no direct intrusion with humans. The researchers used content analysis, namely, thematic analysis to analyse research integrity and research supervision. Allen (2017) stated that "thematic analysis may be used to uncover issues, problems, similarities, and differences as applied to communication" (1757).

The authors assured that trustworthiness in the conducted thematic analysis was established. In other words, both validity and reliability were considered by the authors during the different phases of the thematic analysis. The following table describes the procedures considered for achieving credibility, transferability, dependability and confirmability (Castleberry and Nolen 2018; Nowell et al. 2017) (Tables 1).

Table 1 Establishing trustworthiness during each phase of the thematic analysis

\begin{tabular}{|c|c|c|}
\hline Phase & Concepts & Means \\
\hline \multirow[t]{4}{*}{ Compiling } & Credibility & peer debriefing \\
\hline & Transferability & Thick description \\
\hline & Dependability & $\begin{array}{l}\text { Detailed } \\
\text { documentation }\end{array}$ \\
\hline & Confirmability & Peer checking \\
\hline \multirow[t]{4}{*}{ Disassembling } & Credibility & peer debriefing \\
\hline & Transferability & Thick description \\
\hline & Dependability & $\begin{array}{l}\text { Detailed } \\
\text { documentation }\end{array}$ \\
\hline & Confirmability & Peer checking \\
\hline
\end{tabular}

Reassembling Credibility peer debriefing

Transferability Thick description

$\begin{array}{ll}\text { Dependability } & \begin{array}{c}\text { Detailed } \\ \text { documentation }\end{array} \\ \text { Confirmability } & \text { Peer checking }\end{array}$

Explanation of establishing trustworthiness

The initial list of articles was shared with three peers who stated their views on the topic, themes and overall structure of the first draft of the paper. The peers are academics working at the same institution of the first author. Their feedback concerned the possibility of adding further quotations evidencing the researchers' claims. They also advised on clearly stating the data collection criteria for readership. These comments are well addressed.

Data collection and data compiling procedures are described in detail in the methods' section.

The researchers used detailed documentation for all steps, processes and procedures of data compiling.

The two researchers checked reversely that the compiled data is matching the required objectives of the study.

The peers' concern was related to the addition of more quotes as evidence, and the development of the criteria for data collection. Therefore, this final draft was developed accordingly.

Coding, group and classification of the data are accounted for in detail in the methods' section.

The researchers used detailed documentation for all steps, processes and procedures of data disassembling.

The two researchers checked a couple times that the coding, grouping and classification of the collected data is consistent and goes towards the intended objectives of the study.

The three peers appreciated the proposed themes. However, they agreed that the researchers should stage and clarify whether these themes were generated inductively, or proposed deductively. Also they suggested linking the themes and trying to build a theoretical and/or conceptual framework describing the whole phenomenon of research integrity and research supervisor.

Final decided-upon themes and generating the supporting data are thoroughly explained in the methods' section.

The researchers used detailed documentation for all steps, processes and procedures of data reassembling. 
Table 1 (continued)

\begin{tabular}{|c|c|c|c|}
\hline Phase & Concepts & Means & Explanation of establishing trustworthiness \\
\hline & & & $\begin{array}{l}\text { The researched verified and discussed that the examined } \\
\text { themes are matching the objectives of the study. }\end{array}$ \\
\hline \multirow[t]{4}{*}{ Interpreting } & Credibility & peer debriefing & $\begin{array}{l}\text { The peers advised to either refer to certain contexts with } \\
\text { evidence from the collected data or make it general. } \\
\text { This has lead to either providing evidence or deleting } \\
\text { statements without evidence. }\end{array}$ \\
\hline & Transferability & Thick description & $\begin{array}{l}\text { Interpretation of the collected evidence for the examined } \\
\text { themes is detailed in the procedure section. }\end{array}$ \\
\hline & Dependability & $\begin{array}{l}\text { Detailed } \\
\text { documentation }\end{array}$ & $\begin{array}{l}\text { The researchers used detailed documentation for all steps, } \\
\text { processes and procedures of data interpretation. }\end{array}$ \\
\hline & Confirmability & Peer checking & $\begin{array}{l}\text { The researchers checked the contribution of one another } \\
\text { towards consistent interpretation of the collected data. }\end{array}$ \\
\hline \multirow[t]{4}{*}{ Concluding } & Credibility & peer debriefing & $\begin{array}{l}\text { The first peer raised the issue of the introduced general } \\
\text { conclusion for all supervisors and revising the } \\
\text { possibility to be specific as this generalisation might be } \\
\text { different from one context into another. The second } \\
\text { and third peers raised the issue of why the conclusion is } \\
\text { directed with messages to several parties: supervisors, } \\
\text { supervisees, policy-makers and administrators. In other } \\
\text { words, this peer reviewing suggested a focused party to } \\
\text { be directed via this research. }\end{array}$ \\
\hline & Transferability & Thick description & $\begin{array}{l}\text { Inferencing criteria for the conclusion are approached in } \\
\text { the methods' section. }\end{array}$ \\
\hline & Dependability & $\begin{array}{l}\text { Detailed } \\
\text { documentation }\end{array}$ & $\begin{array}{l}\text { The researchers used detailed documentation for all steps, } \\
\text { processes and procedures of generating concluding } \\
\text { remarks. }\end{array}$ \\
\hline & Confirmability & Peer checking & $\begin{array}{l}\text { The two authors and three peers checked the conclusions } \\
\text { and their relevance to the objectives, the collected data } \\
\text { and the findings. }\end{array}$ \\
\hline
\end{tabular}

\section{Research Design}

The study aims to establish a stronger relationship between research supervision and research integrity and a stronger integration between the two. In return and in effect, this helps empower both supervisors and supervisees to create better relationships and ensure the conduction of research with integrity. Figure 2 shows the study design.

\section{Research Procedures}

The authors collected data on research integrity and research supervision using international databases as per detailed above. They focused on generating data supporting the three predetermined themes (i.e. research integrity and research supervision relationship, research supervision at danger and danger at research supervision). The generated data included quotes, paraphrasing and summarisation of relevant supporting ideas, findings and conclusion related to these three themes. The generated data was merged with views of the researchers on these three themes forming a discussion and evidence following the thematic analysis steps. The authors of this paper detailed above the steps following the five phases of thematic analysis. The list of references includes both the data sources list and the reference list. The references 


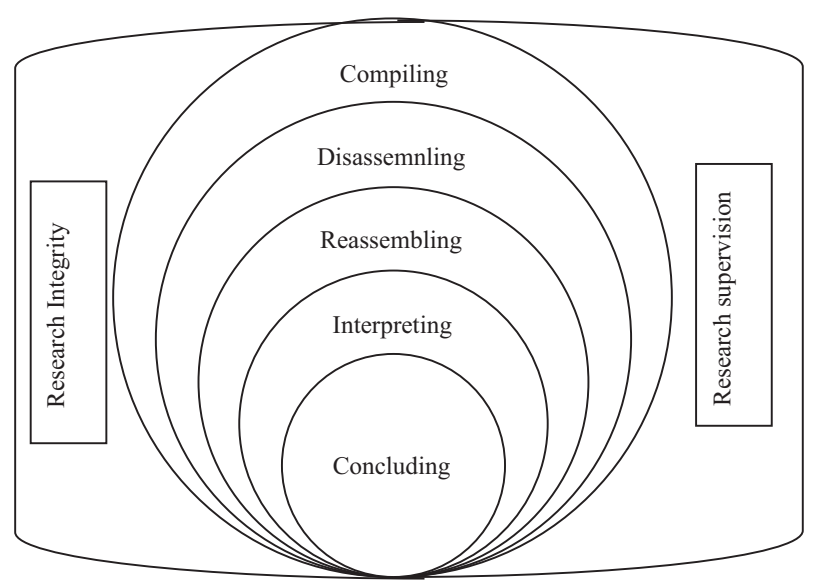

Fig. 2 Study design

that were not used as sources data are marked with an asterisk (*). The three themes are presented below with a thematic mapping for each at the end of each section. The concluding section includes a conceptual map — brining the three themes together.

\section{Research Findings}

\section{Research Integrity and Research Supervision: Relationship}

The increasingly high competition of publications indicates the significantly dire need for stronger research integrity in all research and study fields. Research integrity associated with research ethics application (Steneck 2006) is in contrast to misconducts in research such as falsification, fabrication or plagiarism (Resnik et al. 2015). Research misconducts can occur due to internal factors (such as lack of academic skills, personal pressure, and pride) and/or external factors (such as ICT and web, control over students' performance, and teaching) (Fatima et al. 2019). Betrayal of truth (falsification and fabrication), or that of trust (plagiarism, irreproducibility and inadequate research practice) is a typical classification of research misconducts (Kuroki 2018).

Research supervision is an activity that is meant to provide advice, funding and emotional support (Pyhältö et al. 2015). This advice is basically related to teaching supervisees research skills, research ethics and how to apply them in reality. The development of research skills and the true application of research ethics lead to stronger research integrity. However, this demands a full mastery of research skills and research ethics on the part of research (and workplace) supervisors (even experienced ones) who also need "to keep up to date ... [and] understand more about the growing field of research ethics, intellectual property.... (Lee 2018, 889). It also relies on the relationship between supervisors and supervisees. If this relationship is misused in one way or another, it actually compromises research integrity as the following statement reads:

... the traditional culture of respecting for mentors and elder people strengthens the hierarchy between the senior and junior researchers. The hierarchy not only influences 
the health of the student-promoter relationship, but also compromises research integrity. For example, the promoter or the senior researcher may claim the position of the first author of a manuscript written by a $\mathrm{PhD}$ student, while the $\mathrm{PhD}$ student cannot say no to that, since his/her future more or less depends on a good relation with the promoter. Some students perceive this as acceptable due to their respect for the promoter ( $\mathrm{Li}$ and Cornelis 2018, 363).

In their comparative study, $\mathrm{Li}$ and Cornelis (2018) also reported that 'researchers in the contexts of China and Finland 'still hold a less determined or neutral attitude towards some research misbehaviors' (364) and this could be due to the lack of training on research integrity. They also informed that Chinese researchers were 'more flexible than the Flemish in violation of such values as honesty, fairness, and verifiability' (Li and Cornelis 2018, 365). While searching for relevant studies, the authors have found that many studies reported upon the research supervision in the Chinese context, which is an interesting matter to investigate further. For example, these studies report that supervisors do not encourage their supervisees towards creativity, or engaging them to become members of the scholarly community (e.g. Shen and Chen 2018). Further, ethical considerations such as falsification and plagiarism are not paid attention by supervisors (Zhou et al. 2010; Rong 2011; Wu et al. 2012 as cited in Peng 2015). Supervisees are not satisfied for a number of reasons such as inadequate supervision, insufficient time and efforts, and lack of research competence (for details, see Peng 2015, 9395). The review paper of Peng (2015) also provided critical suggestions for the improvement of research supervision in China. Of course, the research supervision quality differs from one university to another, as it is also the case with universities in all contexts. Meanwhile, it differs from one scholar to another within the same institution and/or department.

The academic capacity of supervisors is a one crucial factor for the success of a thesis/ dissertation (Dietz et al. 2006 as cited in Simon 2014). Having knowledge about research skills is also significant but not enough; possessing other skills as stated in the following quote is also of equal significance:

Academics may have excellent research skills and be highly respected in their field of study. However, there is often little preparation for the role of supervisor, which requires particular communication skills, personal qualities; and the building of a working and a personal relationship with the doctoral student (Simon 2014, 537-538).

Supervisors appear to learn about supervision via reflecting on how they were supervised (Doloriert et al. 2012 as cited in Simon 2014). If the supervision is positive, it will positively influence the supervision practices, and the other way around is true. In other words, the presence of supportive and friendly climate is positive towards strengthening research integrity (Bouter et al. 2016). Therefore, it is safe to note down that there is a strong connection between research supervision (particularly during the stage of master thesis supervision), and research integrity. For this specific reason, it is valuable for research supervisors to pay a greater attention towards this particular stage of training, and do their best toward providing critical, constructive, and practical supervision with a view to building and enhancing research integrity. This also depends on the type of relationship between supervisors and supervisees, which is detailed below.

The relationship between supervisors and supervisees is important and should serve in the betterment of the thesis/dissertation. Researchers have described the relationship between supervisors and supervisees in several contexts. For example, Ribau (2018) used the term 
'attrition' to describe the situation of doctoral supervision in Portugal and reported that only good quality supervision can help reduce the rate of 'attrition' relationship between supervisors and supervisees. However, good supervision is based on trust between supervisors and supervisees, and the presence of similar research interests. Meanwhile, lack of interest, support, and presence of conflict are key factors for low supervision in Australian undergraduate studies (Roberts and Seaman 2018, 33). By applying the five-principle model of Kitchener in analysing data, Löfström and Pyhältö (2017) reported that doctoral supervision should help strengthen the learning and application of stronger ethical norms. Drawing upon the five-principle model of Kitchener (1985, 2000as cited in Löfström and Pyhältö 2017), the following figure depicts the relationship between supervisors and supervisees and the main categories and key factors that lead to the violation of research integrity in supervision (Figs. 3, 4,5 and 6).

The presence of functional supervision is more meaningful for supervisors and supervisees (Elliot and Kobayashi 2018). This supervision is further significant for doctoral students who are also forming the identity of becoming supervisors (Halse 2011). In this concern, Lee (2008) proposed that the functional roles of a supervisor (e.g. enculturation, critical thinking, emancipation and emotional intelligence within the relationship development) are effective for quality supervision. Drawing on the works of Lee $(2008,18)$, the following figure illustrates the levels of supervision and research integrity violation.

The base level is the largest and operates at all institutions with a focus on performing the basic requirements for supervision and research integrity. The second level refers to motivating supervisees to develop their academic works excellently. However, violation of research integrity could take place when a supervisor assigns seniors to supervise juniors and the supervisor-

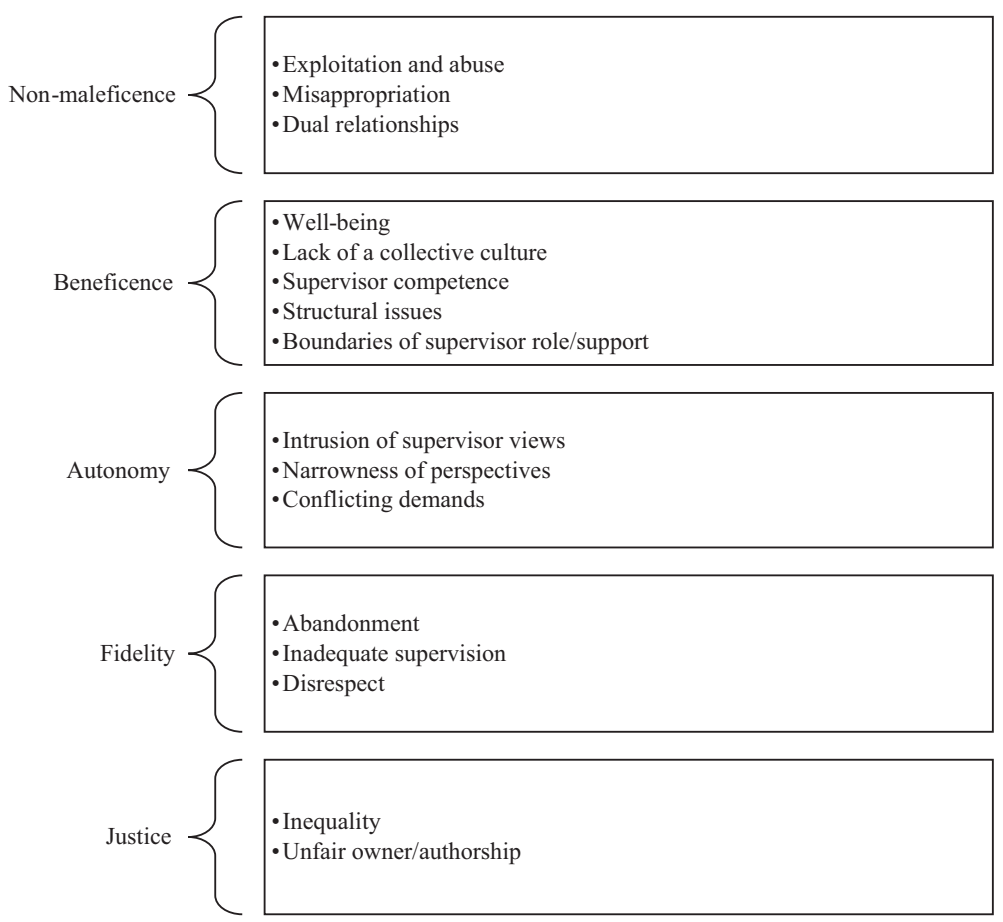

Fig. 3 Research integrity impacted by supervisor-supervisee relationship 


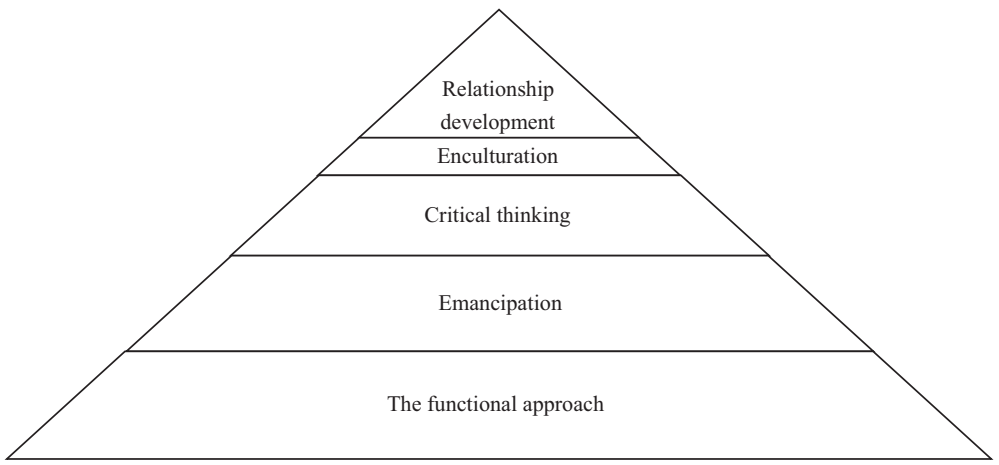

Fig. 4 Levels of supervision and research integrity violation

mentoring both seniors and juniors. The third level is related to supervisees' critical thinking development and use in research. This could be encouraged or discouraged by supervisors. The fourth level relates to the formation of self-identity as an independent researcher - enhanced and supported by the first three levels. In other words, should this be the only phase, then, it would turn into the 'ghost supervisor' role where the student is given the full freedom to work and this could affect research integrity more when the supervisee is not well-qualified and remains so after graduation. For well-qualified supervisees, research integrity is overtly violated by losing opportunities that should have been offered and highlighted by their supervisors. The top level is connected to the relationship between the supervisor and the supervisee that -by considering the type of relationship- either enhances or violates research integrity.

\section{Research Supervision at Danger}

It is necessary for research supervisors to equip themselves with all knowledge needed for performing the supervision activity excellently; otherwise, research supervision will be at danger. Many cases show how the research supervision can be at danger. For example, when research knowledge and interpersonal skills (Beasley 1999), and flexibility with several operational roles (Quinn et al. 1996 as cited in Vilkinas 2002) are lacking on the part of supervisors, the research supervision is then at danger. Furthermore, requesting a committee member to ease the processes of the thesis defence for a supervisor's supervisee (Muthanna 2016) shows that the research supervision is at danger. It also implies that the supervisor is aware of the reality that they did not perform the activity professionally, putting it at danger indeed.

Helping supervisees feel 'being like researchers' without imposing on them, and engaging them in a collaborative reflection (Ginn 2014) is significant; however, providing a critical, constructive feedback is further significant since some supervisees (particularly those who would reflect on their peers) may lack sufficient knowledge on the subject-matter under discussion. Such peers might also lack research ethics as well. Moreover, clarifying the intercultural differences and similarities, and stating the research goals supervisees need to achieve, help decrease implicit and explicit misunderstandings during the supervision processes (for details, see $\mathrm{Hu}$ et al. 2016). Nonetheless, less awareness of intercultural issues and lack of pointing them out in advance with supervisees put research supervision at danger. 


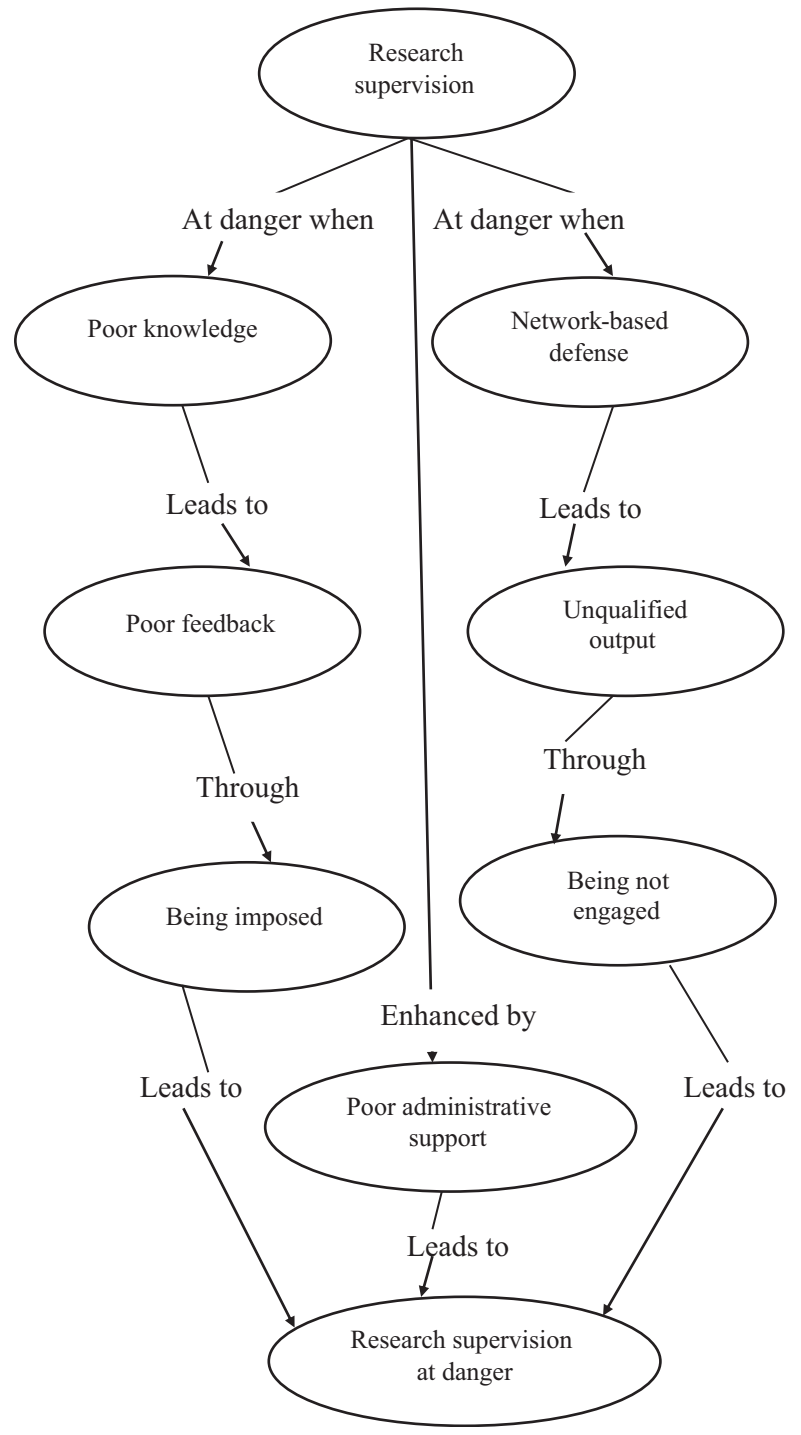

Fig. 5 A thematic mapping of research supervision at danger

Additionally, research supervision can be at danger when there is a lack of departmental support that might bring about less effective relationships between supervisors and (international) students (Cotterall 2015). The complexity of relationships might also force students to have a loneliness life (Elliot et al. 2016) adding to the cultural and linguistic challenges. Therefore, knowing of supervisees well before accepting to supervising them is useful. As students come from different backgrounds (even if they belong to the same nation, they still have different backgrounds), it is valuable for supervisors to be culturally aware and learn how to deal with multicultural backgrounds (Siddiqui and Jonas-Dwyer 2012). It is important that the feedback should be constructive, effective, and useful and fosters a better 
understanding for the supervisees (e.g. Chanock 2010; Poulos and Mahony 2008; Weaver 2006). Otherwise, the supervisees might not feel positive about the feedback. Further, the use of monologue while providing feedback might lead to dissatisfaction on the part of supervisees (Nicol 2010). This dissatisfaction might then lead to producing low quality works, reflecting how research supervision is at danger. Following is a model showing the main factors that place research supervision at danger.

\section{Danger at Research Supervision}

Danger at research supervision occurs for several reasons. Primarily, the violation of research ethics is the main reason for the presence of danger at research supervision. Many cases show how danger is present at the research supervision activity. For example, when supervisors are not practicing academic ethics by themselves, the misconduct of data falsification and plagiarism (e.g. Fang et al. 2013; Rong 2011) becomes common. This carelessness of supervisors towards the implementation of research ethics brings about much danger at research supervision. It actually instigates students to be careless toward practicing research ethics. Further, accepting to supervise many students without making a proper arrangement or allocating a sufficient time (Fang and Li 2009), or providing unfair treatment towards supervisees (Chen et al. 2003) are actions reflecting danger at the research supervision.

Furthermore, danger at research supervision is easily detected when supervision becomes abusive. Abusive supervision relates supervisors' inconsiderate actions or the use of ridiculing, criticizing, or destroying a supervisee's confidence (Tepper 2007). Abusive supervision is destructive, and negatively influences creativity (Meng et al. 2017). It brings about students' distress (e.g. Tepper 2007), life conflict (e.g. Harrison and Westwood 2009; Hoobler and Brass 2006), emotional exhaustion (e.g. Scheuer et al. 2016; $\mathrm{Wu}$ and $\mathrm{Hu} 2009$ ) or vicarious trauma (e.g. Harrison and Westwood 2009). Vicarious abusive supervision is more dangerous and affects any desired results (Harris et al. 2013). Supervisors who 'give their supervisees the impression that they are emotionally unstable, do not do what they have said they would, tend to blame others, and are inaccessible, non-supportive and barely able to satisfy supervisees' expectations' (Meng et al. 2017, 609) are examples of abusive supervisors. Unfortunately, abusive supervision also exists among colleagues at the same institution (e.g. Hershcovis and Barling 2010; Tepper 2007). The implication is that if such colleagues treat one another in such abusive manner, it might be more abusive when it comes to treating their supervisees. These abusive treatments threaten the well-being of students and lead to continual stress that develops to become medically untreated.

Above all, it is catastrophic to read that some supervisors exercise the sexual abuse for the sake of graduation (Zhang 2007). This is the most critical factor that shows the highest degree of danger at research supervision. All types of abusive supervision and the lack of practical implementation of research ethics are catalysts for the presence of danger at the research supervision activity.

In this regard, Chamberlain (2016) proposed ten types of supervisor-supervisee relationships. By expanding the use of this classification, we attempt to explain the 
danger of research supervision through research integrity and creativity levels. The first column shows the type of the relationship and the second one describes this type of relationship. More importantly, the third column identifies the state of the research integrity. We used three indicators: not threatened (+), threatened (-), or could be either threatened, not threatened or a mixture of both $(\#)$. The forth column attempts to predict the creativity level based on the characteristics of the role. We also used three indicators positive (+), negative (-), or could be either positive, negative or a mixture of both (\#). The assigned values for the third column are decided based on the performed roles by both the supervisor and the supervisee. When the supervisor acts as major, boss, leader, VIP, intelligent, absolute decision-maker, etc., and the student is minor, worker, follower, stupid, etc., then such practices threaten the research integrity. For this reason, only two of these 10 types have the mixed value and non-threatened value. For number nine, the supervisor acts as a counsellor and based on the practice of this function, the value can decrease or increase but in all cases there is a positive side since the supervisor is playing the role of a counsellor. In case 10, professionalism is the major role played by the supervisor and this is where research integrity is both overtly and covertly ensured. Creativity has three patterns based on this classification: negative, positive and a mixture of both. Creativity is threatened in most cases due to the overt role of the supervisor in some cases and/or unprofessionalism in some other cases and this pattern is the most frequent one among the ten types. The second pattern is the mixed pattern and has three possibilities for creativity to take place. First, when the supervisee is well-qualified and the "ghost supervisor" is only required to formalise the supervision process. Second, when sexual relationship is taking place between the supervisor and the supervisee and this could psychologically push and/or motivate either or both of the two parties to function creatively, especially the supervisor. Third, when the supervisor acts as a counsellor and based on the professional degree of this counselling and the comprehension level of the supervisee - creativity can sharpen up or down. The third pattern is the positive one where the supervisor provides training and guidance based on observing the weaknesses of the supervisee and working towards producing a skilled researcher/colleague other than being blinded by the concept of producing a rival (Table 2).

Table 2 An illustration of danger at research supervision

\begin{tabular}{llll}
\hline relationship type & characteristics & research integrity indicator & creativity \\
\hline clone & supervisor-based research & - & - \\
cheap labour & major-minor role & - & - \\
ghost & supervisee-based research & - & $\#$ \\
chum & servant-boss role & - & - \\
collateral damage & VIP-ordinary role & - & - \\
combatant & intelligent-stupid role & - & - \\
creepy crawlers & shepherd-herd role & - & - \\
captivate and con & sexual-desire role & - & $\#$ \\
counsellor & expert-patient role & $\#$ & $\#$ \\
colleague in training & major-minor colleague role & + & + \\
\hline
\end{tabular}




\section{Concluding Remarks and Critical Messages}

Research integrity differs from one context to another and from one discipline to another within the same context (Jiang et al. 2013); however, the presence of professional conduct standards (Macfarlane et al. 2014) is important for all supervisors and supervisees worldwide. Real collaboration among supervisors and supervisees helps supervisees develop expertise (Casanave 2019; Saavedra et al. 2019). Following the existing accepted guidelines is productive for both supervisors and supervisees (Mitchell and Carroll 2008). However, these guidelines should be unified for both national and international supervisees to avoid conflicts and research misconducts (Taylor and Bicak 2019). And for further resolution to conflicts among supervisors and supervisees, the presence of a co-supervisor is recommended (e.g., Johansen et al. 2019). However, ensuring that the doctoral supervisees "do not 'fall between two stools' because both supervisors think that the other one is responsible for a particular part of supervision ... [and ensuring] that workplace supervisors feel an important part of the academic team ..." is crucial for successful supervision (Lee 2018, 889).

The following are critical messages to the key stakeholders engaged in preparing higher education policies and their implementation. Putting these critical messages into practice helps in the betterment of the research supervision activity that in return and in effect enhances research integrity.

\section{A Message to Higher Education Policymakers and Administrators}

The establishment of several associations (e.g., American Educational Research Association, (British) Higher Education Academy, European network for research integrity, International Center for Academic Integrity, etc.) is useful in preparing codes and guidelines concerning teaching and/or research supervision. Similarly, establishing and joining such societies enhances a deeper awareness toward a professional planning of institutional policies that ultimately target 'excellence' in teaching and supervision activities. Further education on the effect of abusive/vicarious supervision and on the resolution of decreasing it is also useful for top management/administration (Harris et al. 2013) in strengthening institutional and departmental guidelines and codes that strictly address such issues. It also helps them reflect upon the importance of providing supervisors with quality supervision workshops, and establishing writing centres (for those universities that have not established such centres) that support the development of students' academic writing skills. Organizing undergraduate and graduate courses on research integrity is also a possible policy response ( $\mathrm{Li}$ and Cornelis 2018) towards the improvement of research integrity and supervision. Considering quality rather than quantity helps in achieving quality supervision; admitting a few number of students helps in providing a quality supervision.

Meanwhile, rewarding supervisors and supervisees on the production of accountable theses/ dissertation not only possibly motivates them to collaborate effectively but also encourages other colleagues and supervisees toward the research integrity application and achievement.

\section{A Message to Instructors/Supervisors}

Essentially, it is ethical to acknowledge the presence of many supervisors who are committed to achieving high quality in research integrity and supervision in every nation. 
Similarly, the presence of less ethical, committed and/or well-qualified supervisors also exists (for example, see Hershcovis and Barling 2010; Harrison and Westwood 2009; Hoobler and Brass 2006; Meng et al. 2017; Tepper 2007; Scheuer et al. 2016; Wu and Hu 2009; Zhang 2007). Supervisors play a significant role in either the success or failure of their supervisees' research. They could make students more successful and/or potential supervisors later or the other way around. This demands bearing in mind that the thesis/ dissertation work is simply the starting point for those students who need effective guidance, and that admitting to supervise some research students implies one's acceptance to be ethically responsible for their research behaviour and works. Further, joining such above-mentioned associations, attending supervision workshops, reading different articles on research supervision, and updating one's knowledge are supportive mechanisms in this respect.

For a better communication of ideas/thoughts, supervisors are recommended to improving their fluency and competency in the language used for the production of the thesis, and studying the different backgrounds of their supervisees; actions leading to the smooth continuity of the processes of effective supervision. Further, there is no dispute about the reality that research is based on trust; however, checking up the collected data of one's supervisees is critical and ethical in enhancing research integrity. Allowing senior students (doctoral supervisees) to supervise junior students (master supervisees) might not be an effective decision as they still struggle with their own works.

\section{A Message to Students/Supervisees}

It is useful for supervisees to prepare a clear time plan. This requires setting certain, clear objectives to achieve within the particular supervision period. To avoid confusion and frustration, a student researcher has to have read or continually reads several published scholarly articles so that they obtain sufficient knowledge allowing them to have a clear idea on what they are searching for or analysing.

For international supervisees, understanding the host culture is necessary and helps avoid misunderstanding. Spending time on developing communication skills is not regrettable. Expanding one's global network would also help in getting critical reflections on one's research works.

\section{Conceptual Mapping of the Critical Messages}

Avoiding putting supervision at danger or making danger at supervision helps maintain research integrity. Being ethically aware of the positives and negatives of research supervision is important and helps achieve excellence in supervision. The continuity of professional development concerning research integrity (and the types and forms of research misconduct) and research supervision is an effective way of increasing awareness and maintaining research integrity (e.g., Angelina et al. 2018). Agreeing to supervise some research students indicates one's being ethically responsible for their students' research behavior and works. Finally, while trust is at the heart of research and supervision, checking up the collected data of one's supervisees is still ethically critical in maintaining research integrity. Following is the conceptual map of the main findings reported in this paper (Fig. 6). 


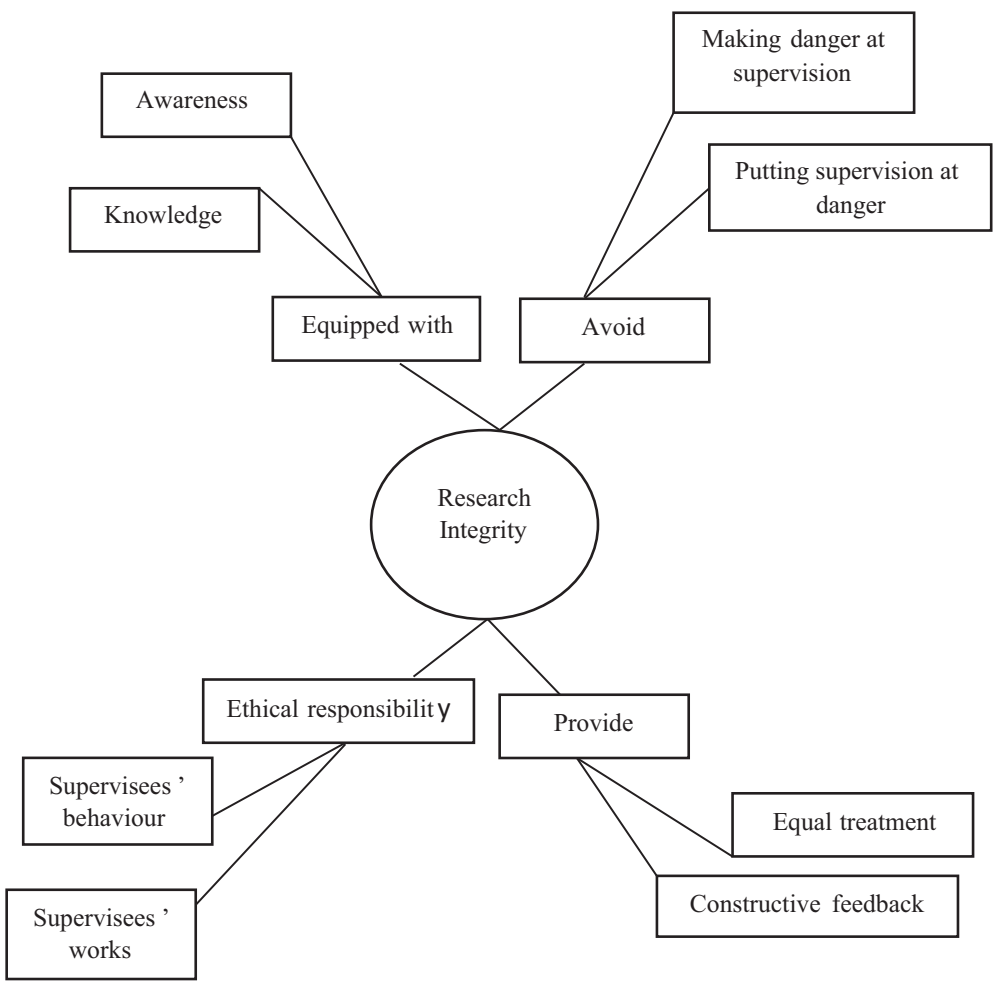

Fig. 6 A conceptual map of research integrity and research supervision, supervision at danger and danger at supervision

Funding Information Open Access funding provided by OsloMet - Oslo Metropolitan University.

Open Access This article is licensed under a Creative Commons Attribution 4.0 International License, which permits use, sharing, adaptation, distribution and reproduction in any medium or format, as long as you give appropriate credit to the original author(s) and the source, provide a link to the Creative Commons licence, and indicate if changes were made. The images or other third party material in this article are included in the article's Creative Commons licence, unless indicated otherwise in a credit line to the material. If material is not included in the article's Creative Commons licence and your intended use is not permitted by statutory regulation or exceeds the permitted use, you will need to obtain permission directly from the copyright holder. To view a copy of this licence, visit http://creativecommons.org/licenses/by/4.0/.

\section{References}

*Allen, M. (2017). The sage encyclopedia of communication research methods (Vols. 1-4). Thousand Oaks: SAGE Publications, Inc.

Anderson, C., Day, K., \& McLaughlin, P. (2006). Mastering the dissertation: Lecturers' representations of the purposes and processes of master's level dissertation supervision. Studies in Higher Education, 31(2), 149-168.

Angelina, P. O., Amin, L., \& Mahadi, Z. (2018). Researchers experience of misconduct in research in Malaysian higher education institutions. Accountability in Research, 52(3), 125-141.

Beasley, N. (1999). Staff development to support research supervision, In Wisker, G. and Sutcliffe, N. (eds.), Good practice in postgraduate supervision (Vol. SEDA paper 106), Staff and educational development association.

Bouter, L. M., Tijdink, J., Axelsen, N., Martinson, B. C., \& Ter Riet, G. (2016). Ranking major and minor research misbehaviors: Results from a survey among participants of four world conferences on research integrity. Research Integrity and Peer Review, 1(17). 
Casanave, C. P. (2019). Performing expertise in doctoral dissertations: Thoughts on a fundamental dilemma facing doctoral students and their supervisors. Journal of Second Language Writing, 43, 57-62.

*Castleberry, A., \& Nolen, A. (2018). Thematic analysis of qualitative research data: Is it as easy as it sounds?. Currents in Pharmacy Teaching and Learning, 10(6), 807-815.

Chamberlain, S. (2016). Ten types of $\mathrm{PhD}$ supervisor relationships: Which is yours. In The conversation Available at: https://world.edu/ten-types-phd-supervisor-relationships/.

Chanock, K. (2010). Comments on essays: Do students understand what tutors write? Teaching in Higher Education, 5(1), 95-105.

Chen, S. H., Song, H., \& Teng, J. G. (2003). A study of relationship between supervisors and their postgraduates in universities - A case study of a university in Central China area. Youth Studies, 6, 27-30.

Cotterall, S. (2015). The rich get richer: International doctoral candidates and scholarly identity. Innovations in Education and Teaching International, 52(4), 360-370.

de Kleijn, R. A. M., Mainhard, M. T., Meijer, P. C., Brekelmans, M., \& Pilot, A. (2013). Master's thesis projects: Student perceptions of supervisor feedback. Assessment \& Evaluation in Higher Education, 38(8), 10121026.

*Dietz, A., Jansen, J., \& Wadee, A. (2006). Effective PhD supervision and mentorship. Amsterdam: Rozenberg Publishers.

*Doloriert, C., Sambrook, S., \& Stewart, J. (2012). Power and emotion in doctoral supervision: Implications for HRD. European Journal of Training and Development, 36(7), 732-750.

Educational Researcher. (2011). Codes of ethics: American educational research association (AERA). Available at http://www.aera.net/Portals/38/docs/About_AERA/CodeOfEthics(1).pdf

Elliot, D. L., Vivienne, B., \& Kate, R. (2016). Searching for 'a third space': A creative pathway towards international $\mathrm{PhD}$ students' academic acculturation. Higher Education Research \& Development, 35(6), $1180-1195$.

Elliot, D. L., \& Kobayashi, S. (2018). How can PhD supervisors play a role in bridging academic cultures? Teaching in Higher Education, 24(8), 911-929.

Fang, H. L., \& Li, Z. Y. (2009). Exploration of supervisor and supervisee harmonious relationship. Modern Education Forum, 3, 28-29.

Fang, R. S., Fang, D. Z., \& Guo, P. F. (2013). A characteristic analysis of academic misconduct in master degree thesis of graduate students. Degree and Graduate Education, 5, 18-22.

Fatima, A., Abbas, A., Ming, W., Hosseini, S., \& Zhu, D. (2019). Internal and external factors of plagiarism: Evidence from Chinese public sector universities. Accountability in Research, 26(1), 1-16.

Ginn, K. (2014). "Being like a researcher": Supervising masters dissertations in a neolibralizing university. Journal of Geography in Higher Education, 38(1), 106-118.

Halse, C. (2011). 'Becoming a supervisor': The impact of doctoral supervision on supervisors learning. Studies in Higher Education, 36(5), 557-570.

Harris, K. J., Harvey, P., Harris, R. B., \& Cast, M. (2013). An investigation of abusive supervision, vicarious abusive supervision, and their joint impacts. The Journal of Social Psychology, 153(1), 38-50.

Harrison, R. L., \& Westwood, M. J. (2009). Preventing vicarious traumatization of mental health therapists: Identifying protective practices. Psychotherapy, Research, Practice, Training, 46, 203-291.

Hemer, S. R. (2012). Informality, power and relationships in postgraduate supervision: Supervising PhD candidates over coffee. Higher Education Research \& Development, 31(6), 827-839.

Hershcovis, M. S., \& Barling, J. (2010). Towards a multi-foci approach to workplace aggression: A meta-analytic review of outcomes from different perpetrators. Journal of Organizational Behavior, 31, $24-44$.

Hoobler, J. M., \& Brass, D. J. (2006). Abusive supervision and family undermining as displaced aggression. Journal of Applied Psychology, 91(5), 1125-1133.

Hu, Y., Van Veen, K., \& Corda, A. (2016). Pushing too little, praising too much? Intercultural misunderstandings between a Chinese doctoral student and a Dutch supervisor. Studying Teacher Education, 12(1), 70-87.

Jiang, H., Emmerton, L., \& McKauge, L. (2013). Academic integrity and plagiarism: A review of the influences and risk situations for health students. Higher Education Research \& Development, 32(3), 369-380.

Johansen, B. T., Olsen, R. M., Øverby, N. C., Garred, R., \& Enoksen, E. (2019). Team supervision of doctoral students: A qualitative inquiry. International Journal of Doctoral Studies, 14, 69-84.

Killian, K. D. (2001). Differences making a difference: Cross-cultural interactions in supervisory relationships. Journal of Feminist Family Therapy, 12(2-3), 61-103.

*Kitchener, K. S. (1985). Ethical principles and ethical decisions in student affairs. In H. J. Canon and R. D. Brown, New directions for student services: Applied ethics in student services (pp. 17-29). San Francisco: Jossey-Bass.

*Kitchener, K. S. (2000). Foundations of ethical practice, research, and teaching in psychology. Mahwah: Lawrence Erlbaum.

Kuroki, T. (2018). New classification of research misconduct from the viewpoint of truth, trust, and risk. Accountability in Research, 25(7-8), 404-408. 
Lee, A. (2008). How are doctoral students supervised? Concepts of doctoral research supervision. Studies in Higher Education, 33(3), 267-281.

Lee, A. (2018). How can we develop supervisors for the modern doctorate? Studies in Higher Education, 43(5), 878-890.

Li, D., \& Cornelis, G. (2018). How do researchers perceive research misbehaviors? A transcultural case study of Chinese and Flemish researchers. Accountability in Research, 25(6), 350-369.

Lovitts, B. E. (2008). The transition to independent research: Who makes it, who doesn't, and why. The Journal of Higher Education, 79, 296-325.

Löfström, E., \& Pyhältö, K. (2017). Ethics in the supervisory relationship: supervisors' and doctoral students' dilemmas in the natural and behavioural sciences. Studies in Higher Education, 42(2), 232-247.

Löfström, E., \& Pyhältö, K. (2018). Research integrity is learned in PhD supervison. Finland. (Accessed in May 19), Retreived from: https://www.vastuullinentiede.fi/en/doing-research/research-integrity-learned-phd-supervision

Macfarlane, B., Zhang, J., \& Pun, A. (2014). Academic integrity: A review of the literature. Studies in Higher Education, 39(2), 339-358.

*Martinson, B. C., Anderson, M. S., \& de Vries, R. (2005). Scientists behaving badly. Nature, 435, 737-738.

Meng, Y., Tan, J., \& Li, J. (2017). Abusive supervision by academic supervisors and postgraduate research students' creativity: The mediating role of leader-member exchange and intrinsic motivation. International Journal of Leadership in Education, 20(5), 605-617.

Milgate, M. (2006). The good supervisor: Supervising postgraduate and undergraduate research doctoral theses and dissertations (a book review). Australasian Marketing Journal, 14(1), 93-94.

Mitchell, T., \& Carroll, J. (2008). Academic and research misconduct in the PhD: Issues for students and supervisors. Nurse Education Today, 28(2), 218-226.

Muthanna, A. (2016). Plagiarism: A shared responsibility of all, current situation, and future actions in Yemen. Accountability in Research, 23(5), 280-287.

Nicol, D. (2010). From monologue to dialogue: Improving written feedback processes in mass higher education. Assessment \& Evaluation in Higher Education, 35(5), 501-517.

Nilsson, J. E. (2007). International students in supervision. The Clinical Supervisor, 26(1-2), 35-47.

*Nowell, L. S., Norris, J. M., White, D. E., \& Moules, N. J. (2017). Thematic analysis: Striving to meet the trustworthiness criteria. International Journal of Qualitative Methods, 16, 1-13.

Peng, H. (2015). Assessing the quality of research supervision in mainland Chinese higher education. Quality in Higher Education, 21(1), 89-100.

Postgraduate Research Experience Survey [PRES], (2019). PRES results 2019-thank you for taking part. Available at: https://warwick.ac.uk/students/dialogue/pres2019/

Poulos, A., \& Mahony, M. J. (2008). Effectiveness of feedback: The students' perspective. Assessment \& Evaluation in Higher Education, 33(2), 143-154.

Pyhältö, K., Vekkaila, J., \& Keskinen, J. (2015). Fit matters in the supervisory relationship: Doctoral students and supervisors perceptions about the supervisory activities. Innovations in Education and Teaching International, 52(1), 4-16.

*Quinn, R., Faerman, S., Thompson, M., \& McGrath, M. (1996). Becoming a master manager (2nd ed.). New York, NY: John Wiley \& Sons.

Resnik, D. B., Neal, T., Raymond, A., \& Kissling, G. E. (2015). Research misconduct definitions adopted by U.S. research institutions. Accountability in Research, 22(1), 14-21.

Ribau, I. (2018). PhD supervision: An exploratory and a preliminary study about the supervisor point of view. PEOPLE: International Journal of Social Sciences, 4(2), 820-836.

Roberts, L. D., \& Seaman, K. (2018). Good undergraduate dissertation supervision: Perspectives of supervisors and dissertation coordinators. International Journal for Academic Development, 23(1), $28-40$.

Rong, C. G. (2011). Exploration of internal motivators for academic misconduct of university teachers. Chinese Higher Education Research, 11, 72-74.

Saavedra, P., Ntontis, E., \& Kyprianides, S. A. A. (2019). PhD supervisors and faculty members might help to avoid burnout as well as enhance engagement and organisational citizenship behaviour (OCB) among PhD students. Official URL: Technical report. University of Sussex https://doi.org/10.20919/Psych(2019).001.

Scheuer, M. L., Burton, J. P., Barber, L. K., Finkelstein, L. M., \& Parker, C. P. (2016). Linking abusive supervision to employee engagement and exhaustion. Organization Management Journal, 13(3), $138-147$.

Shen, W., \& Chen, H. (2018). Chinese doctoral education quality and employment in the context of education expansion. Chinese Education \& Society, 51(3), 155-157.

Shute, V. (2008). Focus on formative feedback. Review of Educational Research, 78(1), 153-189.

Simon, S. (2014). The supervised as the supervisor. Education + Training, 56(6), 537-550.

Steneck, N. H. (2006). Fostering integrity in research, definitions, current knowledge, and future directions. Science and Engineering Ethics, 12(1), 53-74.

Taylor, Z. W., \& Bicak, I. (2019). Academic honesty, linguistic dishonesty: Analyzing the readability and translation of academic integrity and honesty policies at US postsecondary institutions. Journal of Academic Ethics, 17(1), 1-15. 
Tepper, B. J. (2007). Abusive supervision in work organizations: Review synthesis, and research agenda. Journal of Management, 33(3), 261-289.

Vilkinas, T. (2002). The PhD process: The supervisor as manager. Education + Training, 44(3), 129-137.

Walker, J. (1998). Student plagiarism in universities: What are we doing about it? Higher Education Research \& Development, 17(1), 89-106.

Walker, C., \& White, M. (2014). Police, design, plan and manage: Developing a framework for integrating staff roles and institutional policies into a plagiarism prevention strategy. Journal of Higher Education Policy and Management, 36(6), 674-687.

Weaver, M. R. (2006). Do students value feedback? Student perceptions of tutors' written responses. Assessment \& Evaluation in Higher Education, 31(3), 379-394.

Wu, T., \& Hu, C. (2009). Abusive supervision and employee emotional exhaustion. Group and Organization Management, 34(2), 143-169.

*Wu, X. F., Wang, L., \& Zhang, Y. (2012). An investigation and analysis of academic atmosphere and academic ethics of Chinese graduate students. Degree and Graduate Education, 3, 18-23.

Zhang, J. (2007). Research on harmonious relationship between supervisors and supervisees. China Higher Education Research, 9, 19-22.

Zhou, G. L., Mo, J. F., Liu, Q., \& Wang, C. H. (2010). The quality investigation of the PhD candidate education in China [in Chinese]. Social Science Academic Press: Beijing.

Publisher's Note Springer Nature remains neutral with regard to jurisdictional claims in published maps and institutional affiliations. 